\title{
Accelerated Reduction in V(SO_2V) Emissions from the U.S. Power Sector Triggered by Changing Prices of Natural Gas
}

\section{Citation}

Lu, Xi, Michael B. McElroy, Gang Wu, and Chris P. Nielsen. 2012. Accelerated reduction in \(SO_2V emissions from the U.S. power sector triggered by changing prices of natural gas. Environmental Science and Technology 46(14): 7882-7889.

\section{Published Version}

doi:10.1021/es301023c

\section{Permanent link}

http://nrs.harvard.edu/urn-3:HUL.InstRepos:10009464

\section{Terms of Use}

This article was downloaded from Harvard University's DASH repository, and is made available under the terms and conditions applicable to Open Access Policy Articles, as set forth at http:// nrs.harvard.edu/urn-3:HUL.InstRepos:dash.current.terms-of-use\#OAP

\section{Share Your Story}

The Harvard community has made this article openly available.

Please share how this access benefits you. Submit a story.

\section{Accessibility}




\title{
Accelerated Reduction in $\mathrm{SO}_{2}$ Emissions from the US Power Sector Triggered by Changing Prices of Natural Gas
}

\author{
Xi Lu \\ School of Engineering and Applied Sciences, Harvard University, Cambridge, MA 02138, USA \\ Address: Cruft Lab 211a, 19 Oxford St., MA 02138 \\ Email: xilu@fas.harvard.edu \\ Phone: 617-496-6365
}

\section{Michael B. McElroy*}

School of Engineering and Applied Sciences and Department of Earth and Planetary Sciences, Harvard University, Cambridge, MA 02138, USA

Address: 100C Peirce Hall, 29 Oxford St., MA 02138

Email: $\underline{\text { mbm@seas.harvard.edu }}$

Phone: (617) 495-4359

\section{Gang Wu}

Institute of Policy and Management, Chinese Academy of Sciences

15 Beiyitiao Alley, Zhongguancun, Haidian District, Beijing 100190, China, Haidian District, Beijing 100190, China

Email: wugmail@126.com

Phone: 86-10-59358816

\section{Chris P. Nielsen}

Harvard China Project and School of Engineering and Applied Sciences, Harvard University Address: Cruft Lab RM 211, China Project, 19 Oxford Street, Cambridge, MA 02138

Email: nielsen2@fas.harvard.edu

Phone: 617-496-2378

Corresponding Author:

Michael B. McElroy (mbm@seas.harvard.edu) 


\begin{abstract}
Emissions of sulfur dioxide $\left(\mathrm{SO}_{2}\right)$ from the US power sector decreased by $24 \%$ in 2009 relative to 2008. The logarithmic mean Divisia index (LMDI) approach was applied to isolate the factors responsible for this decrease. It is concluded that $15 \%$ of the decrease can be attributed to the drop in demand for electricity triggered by the economic recession, $28 \%$ to switching of fuel from coal to gas responding to the decrease in prices for the latter. The largest factor in the decrease, close to $57 \%$ resulted from an overall decline in emissions per unit of power generated from coal. This is attributed in part to selective idling of older, less efficient coal plants that generally do not incorporate technology for sulfur removal, in part to continued investments by the power sector in removal equipment in response to the requirements limiting emissions imposed by the US Environmental Protection Agency (US EPA). The paper argues further that imposition of a modest tax on emissions of carbon would have ancillary benefits in terms of emissions of $\mathrm{SO}_{2}$.
\end{abstract}

\title{
1. Introduction
}

Overall generation of electricity in the US decreased by $4.1 \%$ between 2008 and 2009. Carbon emissions from the power sector, which accounts for approximately $40 \%$ of total US greenhouse gas emissions, declined over the same period by an even larger factor, by $8.76 \%$ in 2009 relative to 2008 . Part of this reduction was attributed to the recession that set in during late 2008 with an important additional contribution due to a price-induced shift in the generation of electricity from coal to gas. Lu et al (1), using an econometric model, concluded that the increase in the use of natural gas relative to coal was responsible for a $4.3 \%$ reduction in $\mathrm{CO}_{2}$ emissions from the US power sector over and above the $4.1 \%$ reduction attributed to the recession. 
We focus in this paper on the implications of the shift in the power mix and other factors for sulfur dioxide $\left(\mathrm{SO}_{2}\right) . \mathrm{SO}_{2}$ is an important air pollutant responsible for production of sulfate aerosols impacting not only public health $(2,3)$, but also acid rain and potentially climate (4). Recent studies $(5,6)$ suggest that warming of the climate by increasing level of greenhouse gases has been significantly offset by cooling due to the direct and indirect impact of aerosols, with particular attention to the role of sulfur. Combustion of fossil fuels in the electric power sector represents the dominant anthropogenic source of $\mathrm{SO}_{2}$ emissions in the US. Emissions of $\mathrm{SO}_{2}$ in the US amounted to 10.4 million metric tons (MT) in 2008 with $66 \%$ associated with the generation of electricity using sulfur-containing fuels (mainly coal), $28 \%$ from varied industrial activities, with the balance from a combination of onroad and off-road transportation (4.6\%) and other miscellaneous sources $(1.4 \%)(7,8)$. Emissions from the US power sector decreased by $24 \%$ in 2009 as compared to 2008 , from 7.8 MT to 6.0 MT (9). The decrease was significantly greater than the corresponding drop either in total power production or in emissions of $\mathrm{CO}_{2}$. We argue here that the primary factor responsible for the reduction in $\mathrm{SO}_{2}$ emissions in 2008 relative to 2009 involved a decrease in emissions of $\mathrm{SO}_{2}$ per unit of electricity produced (we refer to this as the $\mathrm{SO}_{2}$ emission intensity). Price induced switching from coal to gas also contributed, as did the decrease in total power production. As we shall indicate in what follows, the reduction in $\mathrm{SO}_{2}$ emissions occurred despite the fact that the sulfur content of coal consumed by the power sector was actually higher in 2009 than in 2008.

Our analysis makes use of the Logarithmic Mean Divisia Index (LMDI) approach as described in Section 2. Results are presented and discussed in Section 3. We propose to treat not only what took place on a national scale but also what developed regionally. For the latter purpose, we chose to focus on census regions, building on the earlier $\mathrm{CO}_{2}$ analysis (1). Implications for $\mathrm{SO}_{2}$ of a potential tax on emissions of carbon from the power sector are discussed in Section 4, with discussion included in 
Section 5.

\section{Methodology and Data}

A number of factors is expected to contribute to changes in emissions of $\mathrm{SO}_{2}$ from the US power sector, specifically changes in electricity production, differences in fuel mix, in the sulfur content of fuels (mainly coal and oil), and in the efficiencies for removal of $\mathrm{SO}_{2}$. The fuel mix for electricity generation varies to a significant extent across the US. The bar graphs in Figure 1 illustrate the fractions of electricity that were generated using coal, natural gas and other fuels for different census regions in 2008 with grayscales indicating the strengths of related emissions of $\mathrm{SO}_{2}$. As illustrated in Figure 1, coal is the dominant fuel employed for electricity generation in the West North Central, East North Central and East South Central regions. As a result, $\mathrm{SO}_{2}$ emissions are relatively high in these regions (10) - Other generating sources (including natural gas, hydro power, nuclear, oil and renewables) are more important for New England and for the contiguous Pacific region. Emissions of $\mathrm{SO}_{2}$ are much lower as a consequence in these regions. Alaska and Hawaii were excluded from the Pacific census region since generation of electricity from coal is negligible in these states.

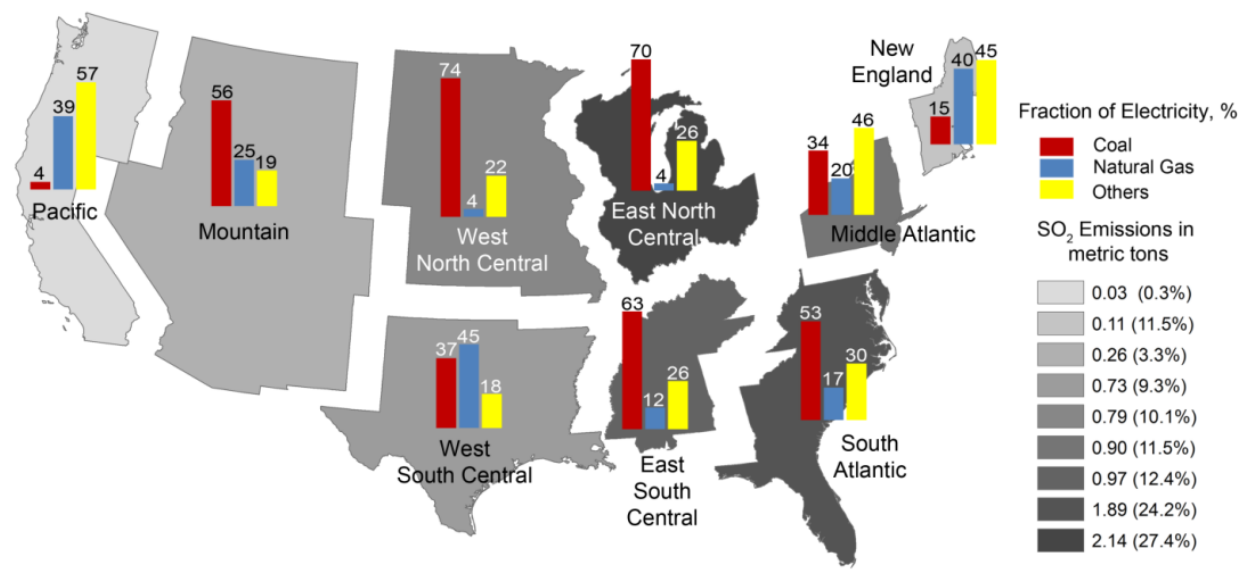

Figure 1 The composition of electricity generation for the nine US census regions in 2008. The grayscales for each region indicate the amounts of $\mathrm{SO}_{2}$ emissions from their power sectors for the same year. 
As indicated by Figure 1, the magnitude of $\mathrm{SO}_{2}$ emissions from the power sector is not determined solely by total power production or by the fraction of electricity generated using coal. The fraction of the total electricity produced using coal in the South Atlantic region is roughly the same as for the Mountain region. While the former generates less than twice as much as electricity as the latter, its emissions of $\mathrm{SO}_{2}$ are more than seven times greater. Other factors, including the $\mathrm{SO}_{2}$ emission intensity must also contribute to the distinction between emissions from the two regions. Similar considerations must be invoked to account for the fact that the Middle Atlantic region is responsible for $12 \%$ of total US power sector $\mathrm{SO}_{2}$ emissions while producing $10 \%$ of the nation's electricity, despite the fact that only $34 \%$ of total power in this region is generated using coal.

Percent changes in electricity generation and $\mathrm{SO}_{2}$ emissions for 2009 relative to 2008 for the nine census regions and for the entire contiguous US are summarized in Table 1 . The changes in electricity generation by energy source varied significantly from region to region between 2008 and 2009 and their impacts on $\mathrm{SO}_{2}$ emissions are similarly complex. The South Atlantic region, for example, was distinguished by an $18 \%$ decrease in generation of electricity using coal, a $21 \%$ increase in production from gas, with a $0.7 \%$ increase from other fuels, accompanied by the largest drop in SO${ }_{2}$ emissions (about $34 \%$ ) as compared with other regions. In the contiguous Pacific region, electricity generated using coal, gas and other sources decreased by $16 \%, 3.8 \%$ and $1.7 \%$ respectively. Despite this, emissions of $\mathrm{SO}_{2}$ increased by $5.4 \%$. Although emissions of $\mathrm{SO}_{2}$ and electricity generation from coal declined simultaneously between 2008 and 2009 in most regions except for the Contiguous Pacific, their change rates exhibited significant differences throughout the nine census regions.

Table 1 Percentage changes of electricity generation and $\mathrm{SO}_{2}$ emissions for the US power sectors in 2009 relative to 2008 for nine census regions and for the entire contiguous US. Data were derived from EIA-906, EIA-920, and EIA-923 (11) and US Energy Information Administration (12). 


\begin{tabular}{|l|c|c|c|c|c|}
\hline \multirow{2}{*}{\multicolumn{1}{|c}{ Regions }} & \multicolumn{4}{|c|}{ Electricity generation } & \multirow{2}{*}{ SO $_{2}$ Emissions, \% } \\
\cline { 2 - 5 } & Coal,\% & Natural Gas, \% & Others,\% & Total, \% & \\
\hline New England & -23 & -0.4 & -1.5 & -4.3 & -8.3 \\
\hline Middle Atlantic & -15 & 9.9 & 1.1 & -2.8 & -27 \\
\hline East North Central & -9.7 & 6.6 & -5.7 & -8.0 & -22 \\
\hline West North Central & -3.3 & -22 & 13 & -0.6 & -18 \\
\hline South Atlantic & -18 & 21 & 0.7 & -5.8 & -34 \\
\hline East South Central & -19 & 27 & 14 & -5.3 & -29 \\
\hline West South Central & -5.3 & -0.7 & 5.5 & -1.3 & -5.8 \\
\hline Mountain & -5.9 & -2.2 & 5.9 & -2.7 & -11 \\
\hline Contiguous Pacific & -16 & -3.8 & -1.7 & -3.1 & 5.4 \\
\hline Contiguous US & -12 & 4.4 & 1.8 & -4.1 & -24 \\
\hline
\end{tabular}

The primary purpose of this paper is to evaluate the relative importance of the different factors noted above in terms of their contributions to the observed changes in 2009 as compared to 2008. Emissions of $\mathrm{SO}_{2}$ for a given region can be expressed as a product of the important relevant factors (total power generation, fraction produced by individual energy sources, and related fractional emissions of $\mathrm{SO}_{2}$ ) according to the KAYA identity (13):

$$
S_{j}=\sum_{i}\left(E_{j} \cdot \frac{E_{i j}}{E_{j}} \cdot \frac{S_{i j}}{E_{i j}}\right)=\sum_{i}\left(E_{j} \cdot f_{i j} \cdot s_{i j}^{E}\right)
$$

where ${ }^{S_{j}}$ refers to the total emissions of $\mathrm{SO}_{2}$ from the power sector in region $\mathrm{j}$; ${ }^{E_{j}}$ denotes the corresponding production of electricity; $f_{i j} \equiv \frac{E_{i j}}{E_{j}}$ represents the fraction of electricity generated from individual sources (coal, natural gas and others); and $s_{i j}^{E} \equiv \frac{S_{i j}}{E_{i j}}$ defines the $\mathrm{SO}_{2}$ emission intensities associated with different fuels (emissions per unit of electricity produced). Definitions of the different variables introduced here are summarized in Table 2. 
The LMDI approach was adopted in order to separate the impacts of the different factors on the overall changes in emissions of $\mathrm{SO}_{2}$. This approach has been widely applied in analyses of energy demand and supply, carbon dioxide emissions, and efficiencies in energy related studies $(14,15)$, and has proved to have advantages over other methodologies in terms of theoretical foundation, adaptability, ease of use, and ease in interpretation of results $(14,15,16)$. With the logarithmic division approach, the unexplained residual terms may be allocated as contributions to the individual factors $(17,18,19)$. If the residual terms are large, this could lead to unavoidable ambiguity in the assignment of influence to specific factors. Arguments supporting the validity of the approach in the present context, in which that the residual terms are relatively small, are presented in the supporting information (SI).

The changes in $\mathrm{SO}_{2}$ emissions for each census region from 2008 to $2009\left(^{\Delta S_{j}}\right)$ may be expressed in the additive form of the LMDI decomposition analysis (14) as a sum of impacts from the individual influential factors as follows:

$$
\begin{aligned}
\Delta S_{j} & =\Delta S_{j}^{E}+\Delta S_{j}^{f}+\Delta S_{j}^{s^{E}} \\
& =\sum_{i} \frac{\log \left(E_{j}^{t}\right)-\log \left(E_{j}^{0}\right)}{\log \left(S_{i j}^{t}\right)-\log \left(S_{i j}^{0}\right)}\left(S_{i j}^{t}-S_{i j}^{0}\right)+\sum_{i} \frac{\log \left(f_{i j}^{t}\right)-\log \left(f_{i j}^{0}\right)}{\log \left(S_{i j}^{t}\right)-\log \left(S_{i j}^{0}\right)}\left(S_{i j}^{t}-S_{i j}^{0}\right)+\sum_{i} \frac{\log \left(s_{i j}^{E_{i j}^{t}}\right)-\log \left(s_{i j}^{E_{i j}^{0}}\right)}{\log \left(S_{i j}^{t}\right)-\log \left(S_{i j}^{0}\right)}\left(S_{i j}^{t}-S_{i j}^{0}\right)
\end{aligned}
$$

Here superscripts 0 and $t$ refer to the beginning and ending years of interest, 2008 and 2009 for the present analysis.

Table 2 Definitions of variables for the LDMI decomposition analysis

\begin{tabular}{|c|l|}
\hline Variable & \\
\hline$i$ & Index of fuels, $i=1,2,3$ for coal, natural gas and other respectively \\
\hline$j$ & Index of US census regions, $j=1-9$ \\
\hline
\end{tabular}




\begin{tabular}{|c|c|}
\hline$S_{j}$ & Total $\mathrm{SO}_{2}$ emissions in $j^{\text {th }}$ census region \\
\hline$E_{j}$ & Total electricity generation in $j^{\text {th }}$ census region \\
\hline$S_{i j}$ & $\mathrm{SO}_{2}$ emissions from electricity generation using $i^{\text {th }}$ fuel in $j^{\text {th }}$ census region \\
\hline$f_{i j}$ & Share of electricity generation using of $i^{\text {th }}$ fuel in $j^{\text {th }}$ census region \\
\hline$S_{i j}^{E}$ & Emissions per kWh of electricity generated using $i^{\text {th }}$ fuel in $j^{\text {th }}$ census region \\
\hline$S_{j}^{E_{c}}$ & Emissions per kWh of electricity generated using coal in $j^{\text {th }}$ census region \\
\hline$S_{j}^{E_{c}}$ & $\mathrm{SO}_{2}$ emissions from electricity generation using coal in $j^{\text {th }}$ census region \\
\hline$E_{c j}$ & Electricity generated from coal in $j^{\text {th }}$ census region \\
\hline$s_{j}^{c}$ & Average sulfur content of coal used for electricity generation in $j^{\text {th }}$ census region \\
\hline$C_{j}^{m}$ & Mass of coal consumed for electricity generation in $j^{\text {th }}$ census region \\
\hline$S r_{j}$ & Average sulfur retention ratio of ash in $j^{\text {th }}$ census region \\
\hline$\eta_{j}$ & Average removal efficiency for $\mathrm{SO}_{2}$ in $\mathrm{j}^{\text {th }}$ census region \\
\hline$H c_{j}$ & Average heat content of coal used for electricity generation in $j^{\text {th }}$ census region \\
\hline$H r_{j}$ & Average heat rate of coal power plants in $j^{\text {th }}$ census region \\
\hline
\end{tabular}


Results from the decomposition process, discussed in Section 3, suggest that changes in $\mathrm{SO}_{2}$ emission intensity for coal-fired systems are primarily responsible for the observed reductions in total emissions. To explore this further, we conducted a second level of analysis decomposing the emission intensity factor into a number of its relevant components. The $\mathrm{SO}_{2}$ emission intensity for coal power plants in region $j$ is defined in this case in terms of a number of related component factors including the efficiencies for removal of $\mathrm{SO}_{2}$ by installed sulfur control systems $\left({ }^{\eta}\right)$, average heat rates for generation of electricity $\left({ }^{H r_{j}}\right)$, and average sulfur contents $\left({ }^{c}{ }_{j}^{c}\right)$ and heat contents $\left(H c_{j}\right)$ for coal consumed, in addition to the retention ratio for the sulfur deposited in bottom ash ( $\left.S r_{j}\right)$. The decomposition process for the emission intensity $\left({ }^{S_{j}}\right)$ is represented then as:

$$
s_{j}^{E_{c}}=\frac{S_{j}^{E_{c}}}{E_{c j}}=\frac{s_{j}^{c} \cdot C_{j}^{m} \cdot\left(1-S r_{j}\right) \cdot\left(1-\eta_{j}\right) 2}{C_{j}^{m} \cdot H c_{j} / H r_{j}}==s_{j}^{c} \cdot \frac{1}{H c_{j}} \cdot H r_{j} \cdot\left(1-S r_{j}\right) \cdot\left(1-\eta_{j}\right) 2
$$

where $C_{j}^{m}$ refers to the total mass of coal consumed in the region. For ease of reference, definitions for all of the variables incorporated in equations (1) - (3) are summarized in Table 2. Contributions due to the heat content of coal, the sulfur retention ratio of ash and the $\mathrm{SO}_{2}$ removal efficiency are represented indirectly by the terms $1 / H c_{j},\left(1-S r_{j}\right)$, and $\left(1-\eta_{j}\right)$. The factor of 2 in the formula reflects the ratio of the molar mass of $\mathrm{SO}_{2}$ to that of sulfur in elementary form. Changes in the $\mathrm{SO}_{2}$ emission intensity from 2008 to 2009 can be represented then using the additive form of the LMDI analysis using an approach similar to that adopted in the first-level analysis: 


$$
\begin{aligned}
\Delta s_{j}^{E_{c}} & =\left\lfloor\Delta s_{j}^{E_{c}}\right]^{c}+\left\lfloor\Delta s_{j}^{E_{c}}\right]^{H c}+\left\lfloor\Delta s_{j}^{E_{c}}\right]^{H r}+\left\lfloor s_{j}^{E_{c}}\right]^{-S r}+\left\lfloor s_{j}^{E_{c}}\right]^{-\eta} \\
& =\sum_{k=1}^{5} \frac{\log \left(a_{k}^{t}\right)-\log \left(a_{k}^{0}\right)}{\log \left(s_{j}^{E_{c} t}\right)-\log \left(s_{j}^{E_{c} 0}\right)}\left(s_{j}^{E_{c} t}-s_{j}^{E_{c} 0}\right)
\end{aligned}
$$

As before, the superscripts $t$ and 0 distinguish between variables referring to either 2009 (t) or $2008(0)$. The term ${ }^{a_{k}}$ in equation (4) refers to the ${ }^{k^{\text {th }}}$ factor ( $\left.\mathrm{k}=1-5\right)$ in equation (3).

The data used in the analysis were derived from publically accessible reports prepared by the U.S. Energy Information Administration (US EIA) and the U.S. Environmental Protection Agency (US EPA). Results for electricity generation in individual census regions and for the contiguous US were computed using monthly, state-by-state reports available on forms EIA-906, EIA-920, and EIA-923 (10). Corresponding data for emissions of $\mathrm{SO}_{2}$ were obtained from forms EIA-767 and EIA-906 (11). The $\mathrm{SO}_{2}$ emission intensity can be defined in terms of the ratio of $\mathrm{SO}_{2}$ emissions from the power sector to the relevant source of electricity. Heat rates for power plants in addition to heat and sulfur contents of coal employed in each census region were computed using a weighted average of fuel consumption data summarized on forms EIA-906, EIA-920, and EIA-923. Sulfur retention ratios for ash were derived using emission factors for $\mathrm{SO}_{2}$ appropriate for different types of boilers and coal, as summarized by the US EPA (20). Average removal efficiencies for $\mathrm{SO}_{2}$ control systems were computed using the methodology described by Zhao et al. (21). Summaries of the data used in this study are presented in Tables S1 and S2 of the SI.

\section{Results}

As described in the previous section, we considered three factors in the first-level LMDI

analysis: electricity generation $\left({ }^{E_{j}}\right)$, fuel mix $\left({ }^{f_{i j}}\right)$ and $\mathrm{SO}_{2}$ emission intensity $\left({ }^{E}{ }^{E}\right)$. The impacts by fuel source of the individual factors affecting $\mathrm{SO}_{2}$ emissions for the entire US from 2008 to 2009, obtained as 
a result of this analysis, are summarized in Figure 2 (Results of analysis of 2009 to 2010 are illustrated in Figure S2 of the SI for the purpose of comparison). The results suggest that, on a national basis, changes in electricity generation, fuel mix, and $\mathrm{SO}_{2}$ emission intensities were responsible for reductions of respectively 0.28 MT, $0.52 \mathrm{MT}$ and $1.1 \mathrm{MT}$ in $\mathrm{SO}_{2}$ emissions between 2008 and 2009, accounting for respectively $15 \%, 28 \%$ and $57 \%$ of the total reduction. The economically driven decrease in electricity demand between 2008 and 2009 clearly contributed to this reduction. Price driven switching from sulfur-rich coal to sulfur-free gas made a further contribution $(1,22)$. The most important influence the analysis suggests, however, involved a significant decrease in the $\mathrm{SO}_{2}$ emission intensity from the coalfired power sector. The coal-fired power plants that were taken offline between 2008 and 2009, responding either to the decrease in demand for electricity or to the more competitive price of natural gas, typically involved some of the oldest, least efficient, plants. And for the most part, these plants had not been equipped with the technology to remove sulfur and other prescribed pollutants included in more modern facilities. The results in Figure 2 indicate that changes in deployment of the coal-fired component of the national power generating system were responsible for as much as $97.6 \%$ of the reduction in national emissions of $\mathrm{SO}_{2}$ between 2008 and 2009.

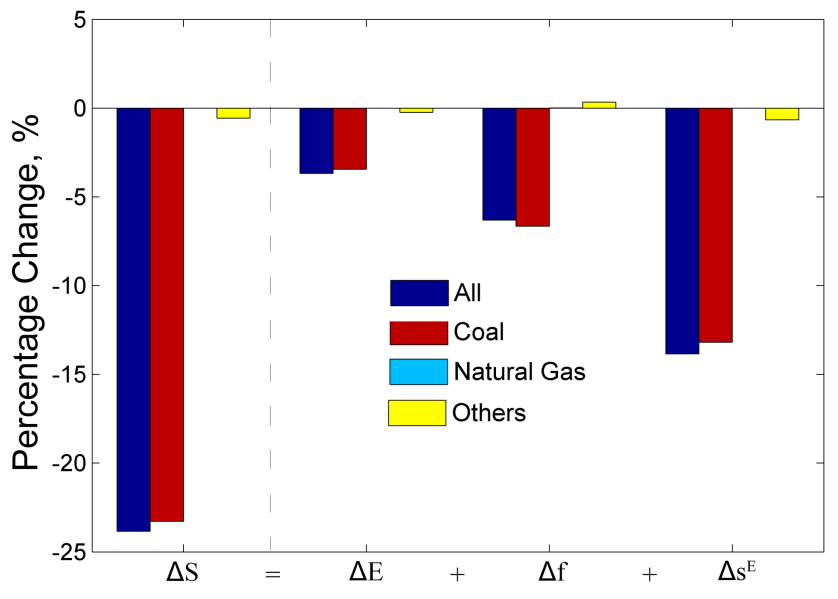

Figure 2 Reductions of $\mathrm{SO}_{2}$ emissions and contributions due to changes in electricity generation ( $\Delta E$ ), fuel mix ( $\Delta f$ ), and $\mathrm{SO}_{2}$ emission intensity $\left(\Delta s^{E}\right.$ ) expressed in terms of percentage for the 
contiguous U.S. in 2009 relative to 2008. Values for natural gas are undetectable given the scales of the vertical axes.

Results obtained by applying the LMDI analysis to the nine census regions are summarized in Figure 3. Reductions in emissions were observed for all regions in 2009 with the exception of the Pacific. The decrease in emissions in the New England and West South Central regions is attributed primarily to changes in the fuel mix, a reduction in the quantity of electricity produced using coal in favor of an increase in production from other sources, mainly gas. $\mathrm{SO}_{2}$ emission intensities increased in the New England and Pacific regions. However, since emissions from these regions are relatively low, these changes had minimal impact on the national scale. For all other regions, $\mathrm{SO}_{2}$ emission intensities decreased, most notably in the West North Central and South Atlantic regions where overall $\mathrm{SO}_{2}$ emissions declined by $18 \%$ and $34 \%$ respectively. Results from the regional analysis are consistent with conclusions drawn from the national study summarized in Figure 2: reductions in $\mathrm{SO}_{2}$ emission intensities were primarily responsible for the nationwide decrease in emissions of $\mathrm{SO}_{2}$ in 2009.

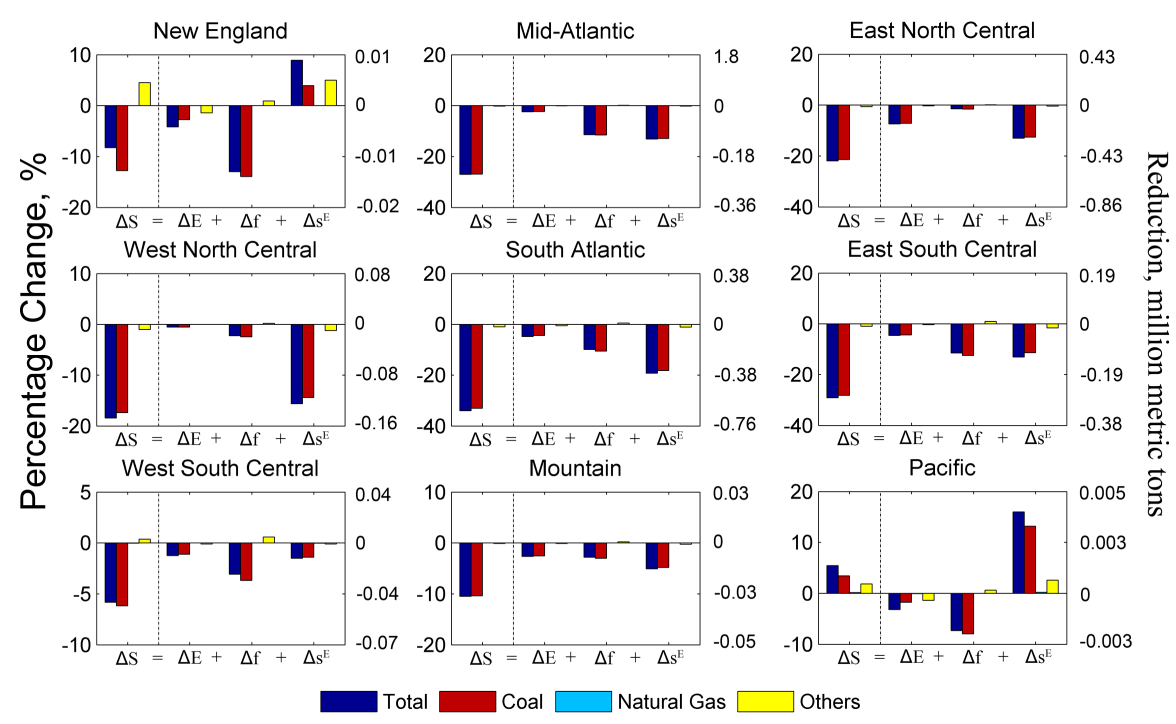

Figure 3 Reductions of $\mathrm{SO}_{2}$ emissions and contributions due to changes in electricity generation ( $\Delta E$ ), fuel mix $\left(\Delta f\right.$ ), and $\mathrm{SO}_{2}$ emission intensity $\left(\Delta s^{E}\right.$ ) expressed in terms of percentage and metric tons for the nine US census regions in 2009 relative to 2008 . Values for natural gas are undetectable in all cases 
given the scales of the vertical axes.

The second-level LDMI analysis described above was applied to a more detailed examination of the factors responsible for the decrease in the emission intensity of the coal-fired component of the national power system between 2008 and 2009. Results for the contiguous US are presented in Figure 4. The analysis suggests that more efficient removal of $\mathrm{SO}_{2}$ as captured by the parameter $\eta_{j}$ made the dominant contribution to the overall reduction in the $\mathrm{SO}_{2}$ emission intensity. The sulfur content of the coal deployed in the power sector in 2009 was actually higher than that used in 2008, contributing thus to an increase in the composite emission intensity. Changes in heat contents of coal used $\left({ }^{H c_{j}}\right)$, retention rates for sulfur in ash $\left({ }^{S r_{j}}\right)$ and heat rates $\left({ }^{H r_{j}}\right.$ ) varied over at most a small range between 2008 and 2009. As indicated in Figure 4, these factors had a relatively minor influence on the net change in the emission intensity over this time period. The uncertainties of these factors may have a considerable impact on the contributions from the changes in $\mathrm{SO}_{2}$ removal efficiencies (the dominant factor identified here) due to the connection defined by equation (3). A sensitivity analysis is included in the $\mathrm{SI}$ to address this issue.

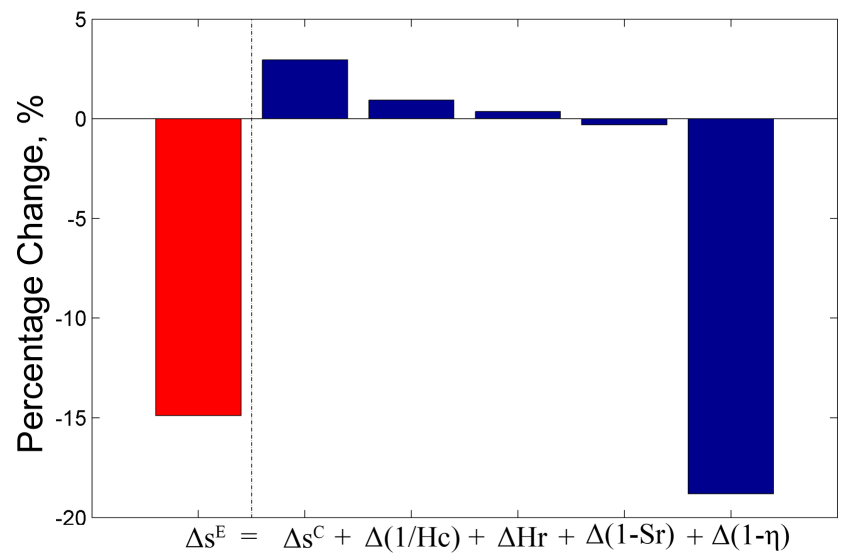

Figure 4 Reductions of $\mathrm{SO}_{2}$ emissions intensity of coal-electricity generation and contributions due to changes in sulfur contents $\left(\Delta s^{C}\right.$ ), heat contents ( ${ }^{\Delta H c}$ ), heat rates of generation ( ${ }^{\Delta H r}$ ), sulfur retention of ash $(\Delta S r)$, and $\mathrm{SO}_{2}$ removal efficiency $(\Delta \eta)$ for the contiguous U.S. in 2009 relative to 
2008.

A combination of factors was responsible for the increase in the emission removal efficiency $\eta_{j}$ . The number of generating systems (primarily coal) equipped with flue-gas desulfurization technology increased from 327 in 2008 to 384 in 2009 contributing to an increase from 140 GW to $168 \mathrm{GW}$ in the capacity of systems equipped to remove sulfur. A further influence involved an important decrease in the fraction of electricity generated using older coal-fired plants in 2009 as compared to 2008 as indicated in Figure S4 of SI. The efficiency for generation of electricity using some of the older coalfired power plants ranges as low as $20 \%$. Operational costs are also typically higher for the older as compared to for more modern plants. As a consequence, the oldest coal plants fall typically on the low end of the merit order scale $(1,23)$. As prices for natural gas decreased relative to coal in 2009 relative to 2008 , and as demand for electricity decreased due to the economic recession, many of the older coal plants, which generally were not equipped to remove sulfur, were either idled or displaced in favor of more cost effective generation using either modern coal plants or by some of the most efficient gas fired systems $(1,24)$.

The results in Figure 4 indicate that the sulfur content of coal consumed in 2009 was marginally higher than that used in 2008 , contributing to an increase in the net intensity emission factor. On a national basis, the sulfur content of the coal consumed in 2009 was 3.2\% higher than in 2008 while the heat content decreased by $1 \%(21)$. The decrease in heat content reflected a modest switch in percentage from higher-energy bituminous coal to lower-energy sub-bituminous fuel. The overall decrease in electricity consumption, in combination with an overall decrease in production using coal, may have reduced the pressure on utilities to limit emissions of sulfur. This could account for the larger fraction of higher sulfur, and potentially cheaper bituminous coal consumed in 2009 as compared to 2008 as indicated in Figure S5 of SI. 
Results from the application of the second-level LMDI analysis to the individual census regions are summarized in Figure 5. For most regions, the relative contributions of the different factors are similar to those inferred for the nation as a whole. The increase in the removal efficiency was greatest as expected in the regions where most of the older coal fired plants were located, notably in the East North Central, East South Central, Middle Atlantic and South Atlantic regions (26). Emissions actually increased in the New England and Pacific regions due primarily in the former case to the use of higher sulfur coal with a further contribution in the latter case associated with a decrease in the removal efficiency.
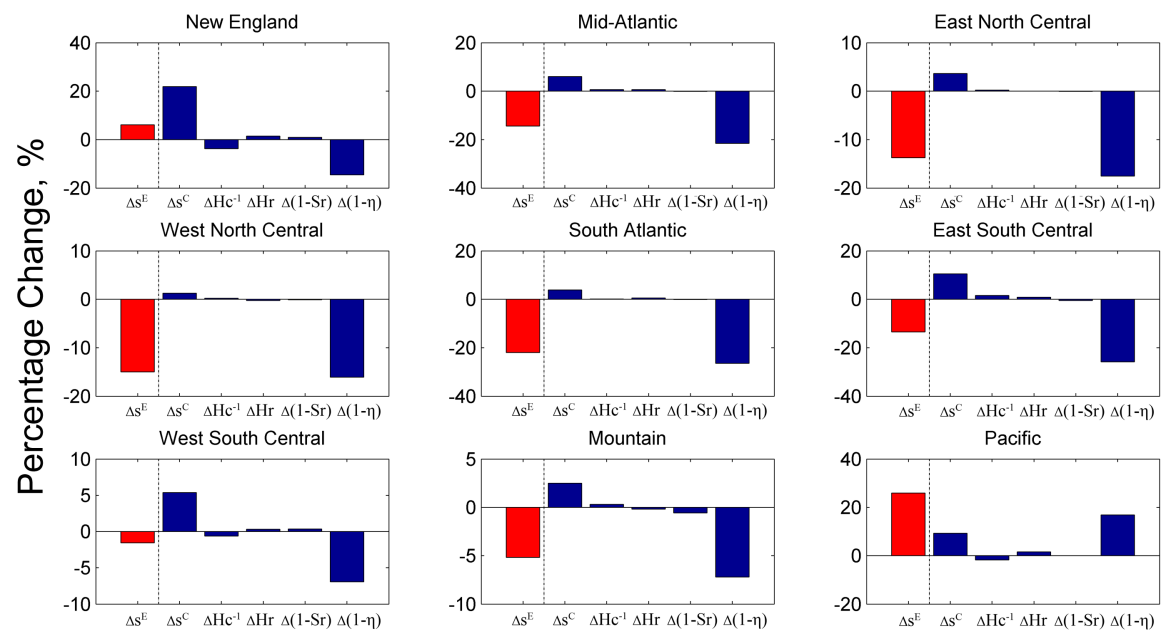

Figure 5 Changes of $\mathrm{SO}_{2}$ emissions intensity of coal-electricity generation and contributions due to changes in sulfur contents $\left(\Delta s^{C}\right.$ ), heat contents ( $\Delta H c$ ), heat rates of generation ( ${ }^{\Delta H r}$ ), sulfur retention of ash $\left({ }^{\Delta S r}\right)$, and $\mathrm{SO}_{2}$ removal efficiency $(\Delta \eta)$ for the nine US census regions in 2009 relative to 2008 .

\section{Immediate Co-benefits of a Carbon Tax}

The potential impact of a tax on carbon emissions imposed on the power sector was discussed by Lu et al (1). A tax on carbon would have an affect similar to that associated with a reduction in the price of natural gas relative to coal, responding to the fact that, per unit of electricity produced, 
emissions of carbon from consumption of gas are only about half of those from coal. Lu et al (1) argued that a modest price on carbon, as low as $\$ 5$ a ton, could result in a significant additional reduction in $\mathrm{CO}_{2}$ emissions. We discuss here the implications of a carbon tax for emissions of sulfur. As in the earlier study, our focus is on the immediate impacts of such a tax. That is to say, we assume that the demand for electricity remains the same and that the response of the generating system to a change in the gas coal price differential is the same as that simulated using the econometric model developed by Lu et al (1).

Regional results from the $\mathrm{SO}_{2}$ analysis are presented in Figure 6. As expected, the additional savings in $\mathrm{SO}_{2}$ emissions are greatest when the difference between gas and coal prices is at a minimum. As indicated in the figure, a tax of $\$ 10$ per ton of $\mathrm{CO}_{2}$ imposed for example in the East South Central region would result in an additional reduction in $\mathrm{SO}_{2}$ emissions of 27,000 tons (3.9\% of total regional emissions) under conditions where the gas-coal cost differential (i.e., the annual cost of gas-fired minus coal-fired electricity) was at a level of 2 cents/kWh. The reduction would be negligibly small if the cost difference for generation of electricity using gas versus coal were to exceed 6 cents $/ \mathrm{kWh}$.

In practice, prices for both gas and coal vary across the country. Adopting reported regional prices for gas and coal in 2009 (11), the results in Figure 6 can be used to calculate the additional savings in $\mathrm{SO}_{2}$ emissions that could have been realized for different levels of a hypothetical tax on carbon. The analysis implies that a tax of $\$ 10$ per ton of $\mathrm{CO}_{2}$ (which would add on average 0.57 cents/ $\mathrm{kWh}$ to the price of electricity) would have resulted in a further reduction of 362,000 tons of $\mathrm{SO}_{2}$ on a national scale in 2009. Gas prices are currently much lower than they were in 2009, approximately $\$ 2.5$ per MMBTU in the first quarter of 2012 as compared to $\$ 4.9$ per MMBTU in 2009 (24). It follows that had prices of gas in 2009 been as low as they are today, the additional savings in emissions of $\mathrm{SO}_{2}$ relative to 2008 projected to have arisen as a result of a tax on carbon of $\$ 10$ per ton $\mathrm{CO}_{2}$ could have been realized at 
even lower levels of this tax.

In estimating the change in $\mathrm{SO}_{2}$ emissions that would have resulted from a carbon tax we assumed that sulfur emissions would be reduced in proportion to the overall reduction in the generation of electricity from coal. In practice we would expect the carbon tax to result in idling of the oldest, least efficient, and probably most polluting, coal power plants. The present analysis most likely underestimates in this case the savings in $\mathrm{SO}_{2}$ emissions that could be realized as an ancillary benefit of a carbon tax.

A carbon tax is expected to promote an increase of demand for natural gas, resulting in an increase in the price of gas and thus an increase in the gas-coal price differential. The reduction in $\mathrm{SO}_{2}$ emissions would be expected in this case to be less than our present estimate. On the other hand, a decrease in demand for electricity responding to the tax-induced increase in electricity prices would result in a reduction in emissions. The effects are obviously offsetting. A detailed analysis of the consequences is however beyond the scope of the present paper.

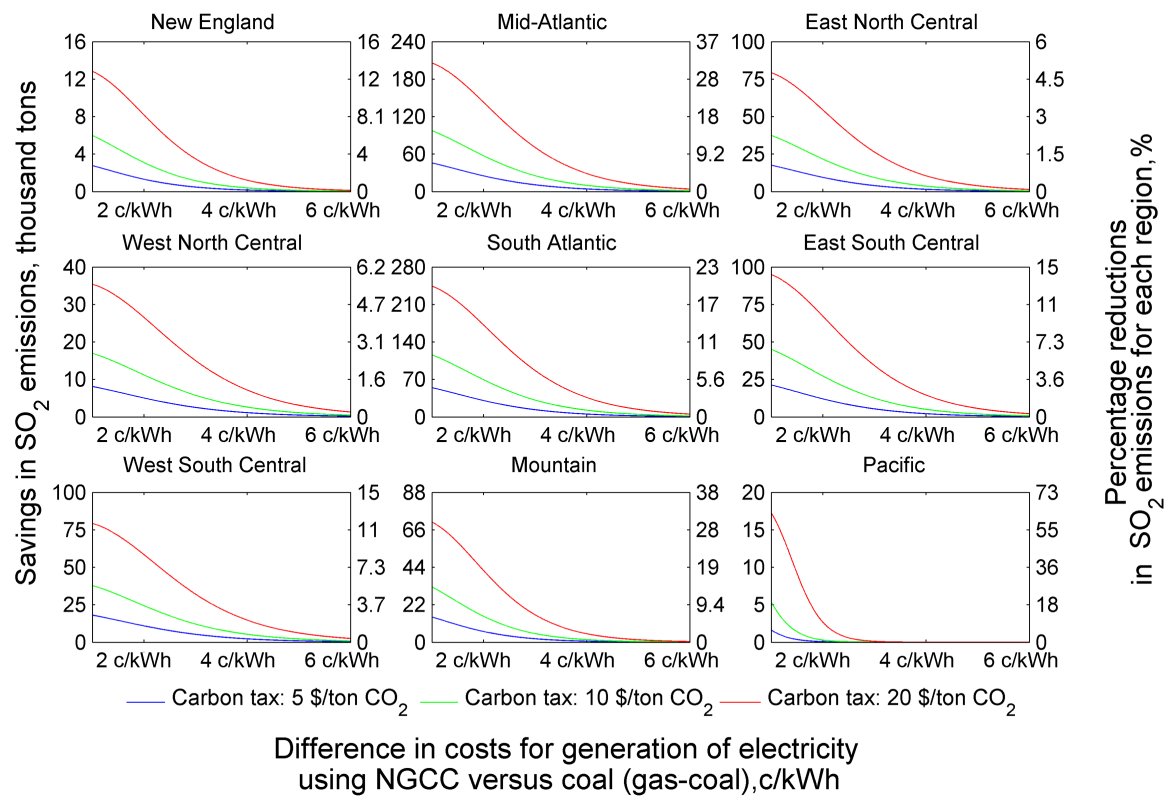


Figure 6 Savings in emissions of $\mathrm{SO}_{2}$ relative to 2008 as a function of the pre-tax difference in costs for power generation using gas rather than coal (gas-coal) as estimated to result from imposition of a carbon tax on the power sector at three levels $\left(\$ 5 /\right.$ ton $\mathrm{CO}_{2}, \$ 10 /$ ton $\mathrm{CO}_{2}$ and $\$ 20 /$ ton $\left.\mathrm{CO}_{2}\right)$. The vertical axes to the left indicate the magnitude of the $\mathrm{SO}_{2}$ reductions measured in thousands of tons $\mathrm{SO}_{2}$. The scales to the right present these data in terms of percentage reductions relative to 2009 for each region.

\section{Discussion}

The present paper focused on analysis of the changes in emissions of $\mathrm{SO}_{2}$ that took place between 2008 and 2009, a period over which recession in the economy led to a reduction in demand for electricity and when prices for natural gas resulted in significant switching of fuel use in the power sector from coal to gas. We have applied the LMDI methodology also to the more extended time period from 1995 to 2010. Results from this analysis are presented in Figure S6 of SI. It suggests that the trend in emissions of $\mathrm{SO}_{2}$ over this period closely followed trends in $\mathrm{SO}_{2}$ emission intensities. Relative to $1995, \mathrm{SO}_{2}$ emission intensities decreased by $16.8 \%$ in 2000 , by $31.7 \%$ in 2005 and by $66.8 \%$ in 2010 , contributing to net decreases in emissions of $2.93 \%$ in $2000,15.8 \%$ in 2005 and $56.1 \%$ in 2010.

The major driver for the decrease in emission intensities is the Acid Rain Program (ARP) established under Title IV of the CAA Amendments of $1990(27,28)$. The key mechanism for the implementation of the ARP involved the introduction of a cap and trade system to limit emissions of $\mathrm{SO}_{2}$ emissions. The cap-and-trade system, initiated in 1995, was expanded in 2000 to include all sources, coal, oil and gas fired generating units, with capacities greater than $25 \mathrm{MW}$. Five years later, in 2005, the US EPA issued the Clean Air Interstate Rule (CAIR) with targets to reduce emissions of $\mathrm{SO}_{2}$ and nitrogen oxides (NOx) from the 28 eastern states and the District of Columbia by 70\% percent in 2015. The CAIR is expected to be replaced by an even tighter the Cross-State Air Pollution Rule (CSAPR) in the near future, requiring reductions in emissions of $\mathrm{SO}_{2}$ of $50 \%$ in 2012 and further reductions of $74 \%$ in $2014(29,30,31)$. As a consequence, the decrease of $\mathrm{SO}_{2}$ emissions was accelerated among the three 
time intervals of 1995-2000, 2000-2005 and 2005-2010.

The results in Figure S6 indicate that the regulations promulgated by the US EPA played an important role in triggering the $67 \%$ decrease in emission intensity inferred to have taken place between 1995 and 2010 (28). The suggestion in this paper is that the recent decrease in prices for natural gas relative to coal is introducing a new consideration into this dynamics. The decrease is prompting replacement of older, less efficient coal-fired plants by newer, more efficient gas combined cycle plants.

The overall increase in removal of sulfur from the coal sector in 2009 reflected in part elimination of the older plants which generally did not incorporate technology for removal of sulfur. If gas prices remain low in the future, we may anticipate that this trend will continue with mothballing of increasing numbers of the more inefficient coal plants, with future increase in the overall efficiency for removal of sulfur from the coal segment of the power generation system. If on the other hand, gas prices recover, the power industry will be compelled to make further, expensive, investments to reduce overall emissions from the remaining coal-fired component of the power sector.

\section{Acknowledgement}

We thank Junling Huang, Jackson Salovaara and Yu Zhao for valuable discussions. This research was supported by the National Science Foundation, grant AGS-1019134. Gang Wu was supported by the National Natural Science Foundation of China, Grant Nos. 70701032 and 71173.

\section{Description of SI}

The uncertainties associated with the LMDI approaches are briefly addressed in Figure S1 and related discussion. Figure S2 summarizes the results of analyzing the changes from 2009 to 2010, when the gas prices increased slightly. A sensitivity analysis of the variables in the second-level LMDI is 
summarized in Figure S3 and related discussion. The percentages of total electricity generation using coal in the US in 2008 and 2009 are presented in Figure S4 as a function of the ages of the generating plants. In Figure S5, the percentages of coal consumed in US electric power generation in 2008 and 2009 by sulfur content are illustrated for four categories of coal. Results of applying the LDMI methodology to a more extended time period, from 1995 to 2000, are presented in Figure S6. Tables S1 and S2 summarize the data used for the first-level and second-level LMDI analyses, and Table S3 summarizes the immediate effect of carbon taxes in reducing $\mathrm{SO}_{2}$ emissions for the nine census regions and for the contiguous US as a whole.

\section{References}

1. Lu, X.; Salovaara, J.; McElroy, M. B., Implications of the Recent Reductions in Natural Gas Prices for Emissions of $\mathrm{CO}_{2}$ from the US Power Sector. Environ. Sci. Technol. 2012, 46, (5), 3014-3021.

2. Desantis, V.; Onufrio, G., Health Risks of $\mathrm{SO}_{2}$ Released from Coal-fired Plants - A Model for General Evaluations. Environ. Res. 1986, 41, (1), 130-138.

3. Avol, E. L.; Jones, M. P.; Bailey, R. M.; Chang, N. M. N.; Kleinman, M. T.; Linn, W. S.; Bell, K. A.; Hackney, J. D., Controlled Exposures of Human Volunteers to Sulfate Aerosols - Health-effects and Aerosol Characterization. Am. Rev. Respir. Dis. 1979, 120, (2), 319-327.

4. Solomon, S.; Qin, D.; Manning, M.; Chen, Z.; Marquis, M.; Averyt, K. B.; Tignor, M.; Miller, H. L., Climate Change 2007: The Physical Science Basis. Cambridge University Press: Cambridge, United Kingdom and New York, NY, USA, 2007; p 996.

5. Hansen, J.; Sato, M.; Kharecha, P.; von Schuckmann, K., Earth's energy imbalance and implications. Atmospheric Chemistry and Physics 2011, 11, (24), 13421-13449.

6. Wild, M., Global dimming and brightening: A review. J. Geophys. Res.-Atmos. 2009, 114.

7. US-EPA 1970 - 2008 Average annual emissions, all criteria pollutants in MS Excel; U.S. Environmental Protection Agency: Washington, DC, June 2009.

8. US-EPA Inventory of U.S. Greenhouse Gas Emissions and Sinks: 1990-2009; EPA 430-R-11-005; U.S. Environmental Protection Agency: Washington, DC, February 15, 2011 ; p 444.

9. US-EIA Electric Power Annual 2010; U.S. Energy Information Administration: Washington, DC, November, 2011; p 102.

10. Booth, W.; Spangler, M. R.; Dorjets, V.; Hutchins, P.; Wirman, C.; Cassar, C.; Hankey, R. S.; Yildiz, O. M.; Peterson, R.; Lillis, K. G.; Bowles, M.; Scott, S. Electric Power Annual 2009; DOE/EIA0348(2009); U.S. Energy Information Administration: Washington DC, April 2011, 2011; p 108. 
11. US-EIA, Form EIA-906, EIA-920, and EIA-923 Data. In April 30 ed.; US Energy Information Administration: 2012; p 520 (http://www.eia.gov/cneaf/electricity/page/eia906_920.html).

12. US-EIA, US Electric Power Industry Estimated Emissions by State, Back to 1990 (EIA-767 and EIA-906). In December ed.; US Energy Information Administration: 2011; p 1130 (http:// www.eia.gov/cneaf/electricity/epa/emission_state.xls).

13. Raupach, M. R.; Marland, G.; Ciais, P.; Le Quere, C.; Canadell, J. G.; Klepper, G.; Field, C. B., Global and regional drivers of accelerating CO2 emissions. Proc. Natl. Acad. Sci. USA 2007, 104, (24), 10288-10293.

14. Ang, B. W., The LMDI approach to decomposition analysis: a practical guide. Energy Policy 2005, 33, (7), 867-871.

15. Liu, L. C.; Fan, Y.; Wu, G.; Wei, Y. M., Using LMDI method to analyzed the change of China's industrial CO2 emissions from final fuel use: An empirical analysis. Energy Policy 2007, 35, (11), 5892-5900.

16. Ang, B. W., Decomposition analysis for policymaking in energy: which is the preferred method? Energy Policy 2004, 32, (9), 1131-1139.

17. Ang, B. W.; Liu, N., Handling zero values in the logarithmic mean Divisia index decomposition approach. Energy Policy 2007, 35, (1), 238-246.

18. Wood, R.; Lenzen, M., Zero-value problems of the logarithmic mean divisia index decomposition method. Energy Policy 2006, 34, (12), 1326-1331.

19. Granel, F. A Comparative Analysis of Index Decomposition Methods. National University of Singapore, Singapore, 2003 (http://scholarbank.nus.edu.sg/bitstream/handle/10635/14229/ GranelF.pdf?sequence=1).

20. US-EPA, Emissions Factors \& AP 42, Compilation of Air Pollutant Emission Factors. In December 28 ed.; US Environmental Protection Agency: 2011; p 97 (http://www.epa.gov/ttn/chief/ap42/ index.html).

21. Zhao, Y.; Wang, S. X.; Nielsen, C. P.; Li, X. H.; Hao, J. M., Establishment of a database of emission factors for atmospheric pollutants from Chinese coal-fired power plants. Atmos. Environ. 2010, 44, (12), 1515-1523.

22. Platt, K. The Implications of Lower Natural Gas Prices for the Electric Generation Mix in the Southeast; U.S. Energy Information Administration: Washington, DC, May 2009, 2009; p 15.

23. Newcomer, A.; Blumsack, S. A.; Apt, J.; Lave, L. B.; Morgan, M. G., Short run effects of a price on carbon dioxide emissions from US electric generators. Environ. Sci. Technol. 2008, 42, (9), 31393144.

24. US-EIA Natural Gas Monthly July 2011; DOE/EIA-0130 (2011/07); US Energy Information Administration: Washington, DC, 2011; $p 107$.

25. US-DOE Form EIA-923: Power Plant Operations Report Instructions; U.S. Department of Energy: Washington, DC, 2011; $p 46$.

26. US-EIA, Form EIA-860 Annual Electric Generator Report. In November 30 ed.; US Energy Information Administration: 2011; p 2242 (http://www.eia.gov/cneaf/electricity/page/ eia860.html). 
27. US-EPA Cap and Trade: Acid Rain Program Basics; Washington, DC, April 14, 2009; p 2.

28. US-EPA Acid Rain Program 2009 Progress Reports U.S. Environmental Protection Agency: Washington, DC, 2010.

29. US-EPA The Cross-State Air Pollution Rule: Reducing the Interstate Transport of Fine Particulate Matter and Ozone; U.S. Environmental Protection Agency: Washington, DC, 2012; 7.

30. Bradley, M. J.; Tierney, S. F.; Atten, C. E. V.; Hibbard, P. J.; Saha, A.; Jenks, C. Ensuring a Clean, Modern Electric Generating Fleet while Maintaining Electric System Reliability; M.J. Bradley \& Associates LLC and Analysis Group: Concord, MA, August, 2010; p 24.

31. Wynne, H.; Broquin, F. D.; Singh, S. U.S. Utilities: Coal-Fired Generation Is Squeezed in the Vice of EPA Regulation; Who Wins and Who Loses?; Bernstein Research: October 12,, 2010; p 109. 